\title{
Development of a test rig to evaluate traction performance of small size rubber tracks in indoor conditions
}

\section{SHOWKAT RASOOL AND HIFJUR RAHEMAN}

Received : 21.07.2017; Revised : 23.08.2017; Accepted : 09.09.2017

See end of the Paper for authors' affiliation

Correspondence to :

SHOWKAT RASOOL

Department of Agricultural and Food Engineering, Indian Institute of Technology, KHARAGPUR (W.B.) INDIA Email : showkat@agfe.iitkgp. ernet.in
- ABSTRACT : Indoor soil bin facility allows experiments to be conducted under controlled conditions to reliably study the wheel soil interaction. An indoor soil bin based test rig has been developed to study the traction performance of small sized rubber tracks. The experimental rig consists of soil bin, track tester, power transmission system, soil mixing and compaction device, loading deviceto vary drawbar pull and control system. The developed system consisted of instrumentation system which included, torque sensor, proximity sensors and load transducer. The parameters measured by these sensors were input torque, actual and theoretical speeds, and drawbar pull, respectively. Traction performance parameters like gross traction ratio (GTR), net traction ratio (NTR), and tractive efficiency (TE) and travel reduction ratio (TRR) were calculated from these parameters. Experiments showed measurements were highly reproducible under different conditions. Preliminary results showed that net traction and gross traction increase with increase in travel reduction ratio and both stabilize after achieving a certain maximum value. Tractive efficiency first increases with increase in travel reduction ratio and then decreases.

KEY WORDS : Track tester, Soil bin, Indoor test rig, Gross traction ratio, Net traction ratio, Tractive efficiency

- HOW TO CITE THIS PAPER : Rasool, Showkat and Raheman, Hifjur (2017). Development of a test rig to evaluate traction performance of small size rubber tracks in indoor conditions. Internat. J. Agric. Engg., 10(2) : 496-502, DOI: 10.15740/HAS/IJAE/10.2/496-502. 